\title{
Aerosol Characterization over a High Altitude Location in Central Himalayas
}

\author{
P. Pant \\ Aryabhatta Research Institute of Observational Sciences (ARIES), \\ Manora Peak, Nainital-263 129, India
}

\begin{abstract}
Our climate is strongly influenced by the manner in which solar radiation is absorbed and scattered in the Earth's atmosphere. Atmospheric aerosols play an important role in modifying the radiation budget of the earth-atmosphere system. Aerosols have a direct impact on the atmosphere as they scatter and absorb solar and infrared radiations and indirectly affect the size distribution of cloud droplets. Hence, the knowledge of aerosols' characteristics is the basic requirement for understanding the impact of aerosols on our environment. In order to delineate the optical and physical properties of aerosols, the collocated measurements of aerosols are carried out at Manora Peak (29.36 N; 79.45 E, altitude 1960 meters), Nainital: a high altitude location in central Himalayas. Since the observing site is located geographically in the free troposphere, thus the aerosol measurements from such a region have the importance for providing a sort of background level of aerosol-parameters against which the impact of aerosol-loading from far-off low laying regions can be assessed. The retrieved parameters of aerosols at ARIES are comprised of aerosol optical depth, mass/number concentrations of composite aerosols, BC mass concentration, total suspended particulate matter, total columnar ozone and water vapor content, meteorological parameters, traces gases etc. The analyzed results have been summarized in the present talk.
\end{abstract}

\section{Introduction}

Atmospheric aerosols (particles of micron or sub-micron size found suspended in the atmosphere), play an important role in modifying the radiation budget of the earth-atmosphere system. Among the various natural and anthropogenic sources of aerosols, man's domestic and industrial activities contribute a dominant share of the tropospheric aerosol burden. Aerosols, both natural and anthropogenic, affect the Earth's climate directly due to the absorption and scattering of solar radiation (Charlson et al., 1992), and indirectly by modifying the microphysics of clouds (Twomey 1977; Albrecht 1989; Rosefield 2000). Further the evaluation of aerosol radiative forcing (ARF) of the atmosphere is assuming increasing importance in climate studies (Haywood and Ramaswamy, 1998; Jacobson, 2001; Ramanathan et al., 2001; Kaufman et al., 2002). Nevertheless, large uncertainties still persist in this area, primarily due to the large heterogeneity in aerosol properties (IPCC, 2007). In this context the Asian region assumes importance because of its high population density and diverse human activities (Moorthy et al., 1999. Satheesh and Ramanathan, 2000; Jayaraman, 2001; Ramanathan et al., 2001; Babu et al., 2002; Seinfeld et al., 2004; Pandithurai et al., 2004; Tripathi et al., 2005). However, most of these studies focused to either urban/semi-urban landmass or oceans adjacent to densely populated coastal belt. Hence, aerosol observations from high- altitude stations have a special significance as the aerosols in this region provide a "far-field picture," quite away from potential sources and are more representative of free troposphere conditions (Pant et al., 2006a). Since the observing site Manora Peak is located geographically in the free troposphere, thus the aerosol 
measurements from such a region have the importance for providing a sort of background level of aerosol-parameters against which the impact of aerosol-loading from far-off low laying regions can be assessed. Further, the measurements of aerosols from so-called free troposphere are also important for the purpose of comparing the measured aerosol-parameters, in campaign mode, as far as an integrated aerosol characterization program is concerned.

Realizing the importance of aerosol study from a high altitude location, a program was initiated at Manora Peak $\left(29.36^{\circ} \mathrm{N} ; 79.45^{\circ} \mathrm{E} ; 1960 \mathrm{~m}\right.$ AMSL), Nainital in the year 2002, in collaboration with the Space Physics Laboratory (SPL), Thiruvananthapuram, to measure the spectral aerosol optical depths (AOD) as a part of Indian Space Research Organization - Geosphere Biosphere Programme (ISRO-GBP). Initially the measurements of spectral aerosol optical depths (AOD) were carried out using Multi Wavelength Radiometer (MWR) designed and developed by the SPL, as AOD $(\tau)$, is a key parameter in order to build up a comprehensive picture of aerosols and their potential impacts on the earth's environment (Moorthy et al., 1999; Satheesh et al., 2002). Later on few other sophisticated aerosol measuring instruments were added for the said purposes. In this paper, we summarized the results of the extensive measurements of optical and physical parameters of aerosols obtained over the years at Manora Peak, Nainital.

\section{Experimental set-up and measurements}

Aerosol measurements are comprised of AOD (MWR and Microtops II Sunphotometer), Black carbon (BC) mass concentration (using seven channel Aethalometer), composite aerosol number concentration (GRIMM : Optical particle counter), total columnar ozone and water vapor content (MWR and Microtops II Ozonometer), Total Suspended Particulate matter (TSPM) using high volume air sampler, and meteorological parameters (Automatic weather station, AWS). Besides these instruments a micro pulse lidar (MPL) system in collaboration with NARL, Gadanki is available to study the vertical extent of aerosol and clouds in the troposphere. More details regarding the site description, instruments and prevailing methodology are given elsewhere (Sagar et al 2004; Pant et al 2006a).

\section{Results and discussion}

Aerosol characterization study at ARIES, Nainital is mainly focused in campaign as well as regular mode of observations. Despite being a pristine high altitude location the monthly mean AOD $\left(\tau_{\lambda=500 \mathrm{~nm}}\right)$ during the Land Campaign II in winter 2004 as part of ISRO-GBP was found to be $0.059 \pm 0.033$; TSPM in the range $15-40 \mu \mathrm{g} \mathrm{m}^{-3}$, mean BC concentration $1.36 \pm 0.99 \mu \mathrm{g} \mathrm{m}^{-3}$, contributed $\sim 5.0 \pm 1.3 \%$ to the composite mass (Pant et al, 2006a). Consequently the inferred mean of single scattering albedo (SSA) was $0.90 \pm 0.03$, indicating significant aerosol absorption. The estimated ARF was as low as $-4.2 \mathrm{Wm}^{-2},+0.7 \mathrm{Wm}^{-2}$ and $+4.9 \mathrm{Wm}^{-2}$, at the surface, the top and the atmosphere respectively. The low value of atmospheric forcing arises primarily from the very low AOD while the forcing efficiency $\sim 88 \mathrm{Wm}^{-2}$ is attributed to the high $\mathrm{BC}$ mass fraction. The BC mass concentration and number concentration of composite aerosols show almost similar trend in diurnal variation (Figure1), indicating low values in the morning hours which gradually increases as the day advances reaching to its summit in late afternoon and thereafter it again decreases to its minimum level during night hours. The observed trend can be explained on the basis of updraft of the polluted emissions from the underlying valley regions to the observing site 
due to boundary layer dynamics (Pant et al., 2006a). Multiyear analysis of diurnal BC variation also shows nighttime low and daytime high with single prominent peak occurring in the late afternoon (before sunset) and $\mathrm{BC}$ is always higher by a factor of about 2 during daytime than the nighttime BC at Nainital. On the contrary this trend of diurnal BC variation is quite opposite to those in low altitude regions (Tripathi et al., 2005; Begum et al., 2009). Seasonally, BC mass concentrations were higher during spring (with a mean value of $1.34 \pm 0.05 \mu \mathrm{g} \mathrm{m}^{-3}$ ), which are attributed to lifting up of pollutants from the valley (below the mountain peak) by the convective boundary layer and increased local emissions. The concentration decreased by a factor of 2 in summer $(0.53 \pm 0.02)$ and recovered during autumn $(1.03 \pm 0.04)$. The long-term average value was $0.99 \pm 0.02 \mu \mathrm{g} \mathrm{m}^{-3}$ (Dumka et al., 2010).
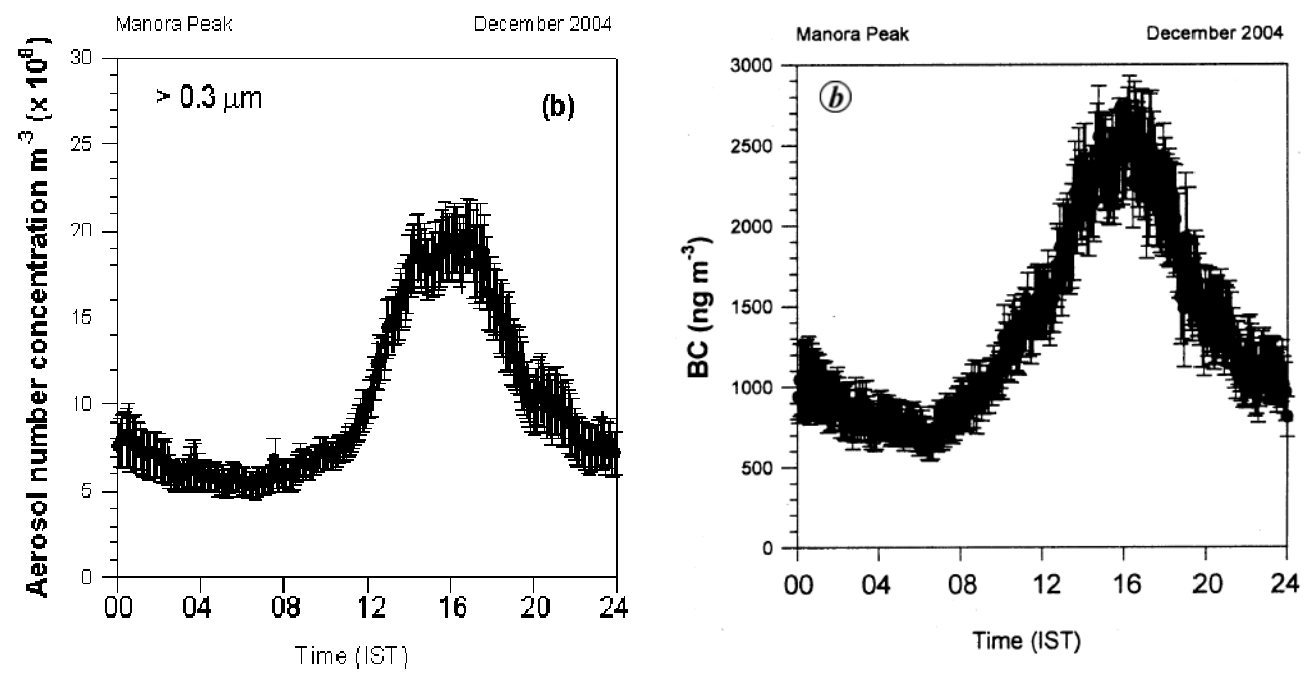

Figure 1: Monthly mean diurnal variation of composite aerosol number concentrations (left) and BC mass concentration (right), during December 2004.

On the other hand the multiyear observations of AOD also reveal very low $\left(\tau_{\lambda=500 \mathrm{~nm}} \leq 0.1\right)$ in winter (Dumka, et al., 2008) sometime these are comparable to the Antarctic environment and increased rather steeply to reach high values $\left(\tau_{\lambda=500 \mathrm{~nm}} \sim 0.5\right)$ in summer (Figure 2, left). AOD during summer can be attributed to the updraft of pollutants from valley regions below the observing site through the strong convective eddies, leading to increased vertical mixing that brings up the pollutants to higher levels. On some occasions higher AOD are also observed which may be due to the aerosol loading by the wind-blown dust particles that are originated at far off regions during intense dust storms and reaching to the elevated site through long range transport phenomenon. Aerosol number concentrations in the coarse and giant modes are found to be five $\left(26 \times 106 \mathrm{~m}^{-3}\right)$ and ten $\left(17.2 \times 103 \mathrm{~m}^{-3}\right)$ times higher during the dust event as compared to their respective normal mean values. AOD also show two to four times increases, particularly at longer wavelengths suggesting increase in the concentrations of coarse and giant particles (Hegde at el., 2007).

Short-period fluctuations (within a daytime) are also observed in the AODs. The boundary layer dynamics plays a key role in transporting aerosols from the polluted valley region to higher altitudes causing large contrast in AODs between forenoon (FN) and afternoon (AN) as shown in 
Figure 2, right. Columnar number size distribution, deduced by using inversion of spectral AOD show bimodal (combination of power law and uni-modal log normal) distributions, with a prominent secondary mode (coarse mode) occurring at $r>0.5 \mathrm{~m}$, while the primary peak (of fine mode aerosols) does not appear explicitly (Dumka etaal., 2009). The evolutionary trend in the size distribution of aerosol particle concentrations during winter shows that the growth of supermicron particles is faster than particles of total and sub-micron size ranges as the day advances (Pant et. al., 2006b).
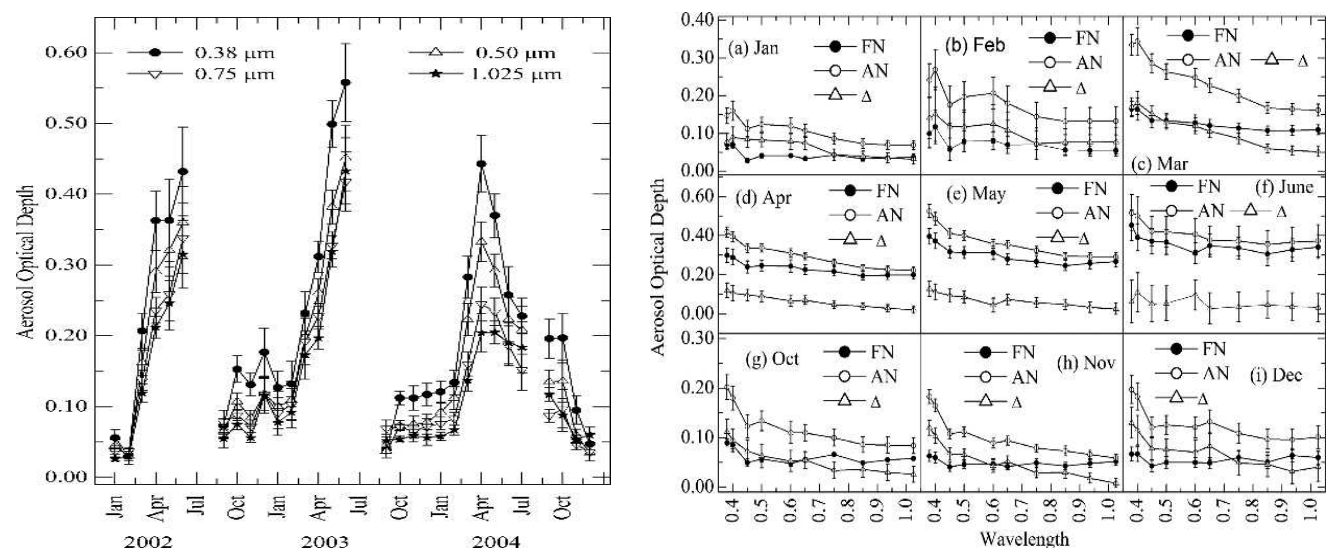

Figure 2: Monthly mean variations of AOD (left) and AOD averaged separately for FN and AN, and their difference as a function of wavelength (right).

The diurnal variation of $\mathrm{BC}$ mass and aerosol-number concentrations as well as forenoon / afternoon AOD discrepancy can be best explained on the basis of day time boundary layer evolution over the observing site. To the North-East of the Manora Peak, the hilly terrain of the Central Himalyan ranges is prominently located where anthropogenic activities are absent or negligible. On the other hand the South-West is predominantly covered by the plain areas $(<0.3$ $\mathrm{km} \mathrm{msl}$ ), merely at an aerial distance of about $10.0 \mathrm{~km}$, which are having strong anthropogenic sources. Once the daytime temperature rises due to the convection processes the $\mathrm{BC}$ aerosols as well as the tapped particles are lifted up in to the atmosphere, which facilitates the transport of pollutants from source regions (valley) to higher altitudes by convective mixing. Owing to which day time high value in the observed $\mathrm{BC}$ mass and aerosol number concentration is found at Nainital (a high altitude location), attributing some sort of updraft of BC aerosols as well as aerosol number concentration due to the atmospheric boundary layer dynamics.

The mixing process of aerosols is also reflected as an enhancement in the observed AOD during the afternoon hours, at the observing site. The afternoon peak in the diurnal variation of $\mathrm{BC}$ mass and aerosol number concentrations as well as afternoon AOD enhancement can be attributed to the vertical transport of pollutants from the near-by polluted urban and valley regions, which were initially confined to lower heights in the night and early morning due to the low-level inversions, but are released to greater heights $(>2 \mathrm{~km})$, as the boundary layer evolves upward. It is an established fact that populated area produces more pollutants confining them within the atmospheric boundary layer (Stull, 1999). During night the majority of aerosol concentration lies below the mountain peaks (in the valley as residual layer), due to capping inversion process that caps a convective boundary layer, consequently preventing the convective elements from rising higher into the atmosphere (Vladimir \& Eichinger, 2004). As the day advances, sun warms the 
surface; convective plumes transport the emissions including updraft of contained pollutants from the surface layer to the higher level in the atmosphere, which facilitates an enhancement in BC mass as well as aerosol number concentration. Hence an updraft of pollutants from valley regions to higher levels tacitly contributes to the enhancement of $\mathrm{BC}$ and number concentration in the observed diurnal variation at Manora Peak.

\section{Acknowledgement}

The aerosol characterization study at ARIES is being carried out as a part of ISRO-GBP. The author is grateful to the Directors of the ARIES, Nainital, and the SPL, Thiruvanathapuram, for their constant support and encouragement. He is also thankful to all scientists for their indefatigable efforts for making fruitful scientific contributions in the field of atmospheric science at ARIES, Manora Peak, Nainital.

\section{REFERENCES}

[1] Albrecht B. A., Aerosols, cloud microphysics and fractional cloudiness, Science 245, 1227-1230, 1989.

[2] Babu S., et al., Aerosol radiative forcing due to enhanced black carbon at an urban site in India, Geophys. Res. Lett., 29(18), 1880, doi:10.1029/2002GL015826, 2002.

[3] Beegum S. Naseema, et al., Spatial distribution of aerosol black carbon over India during pre-monsoon season, Atm. Environ., 43, 1071-1078, 2009.

[4] Charlson, R, J., et al., Climate forcing by anthropogenic aerosol, Science, 255, 423-430, 1992.

[5] Dumka U. C. et al., Short-Period Modulations in Aerosol Optical Depths over the Central Himalayas: Role of Mesoscale Processes, DOI: J. of Applied Meteorology and Climatology, 10.1175/2007JAMC1638.1, 2008.

[6] Dumka U. C., Sagar R. and Pant P., Retrieval of Columnar Aerosol Size Distributions from Spectral Attenuation Measurements over Central Himalayas, AAQR, 9, 344-351, 2009.

[7] Dumka U. C. et al., Characteristics of aerosol black carbon mass concentration over a high altitude location in the Central Himalayas from multi-year measurements, Atm. Res. 96, 510-521, 2010. 
[8] Haywood J. M. and Ramaswamy V., Global sensitivity studies of the direct forcing due to anthropogenic sulfate and black carbon aerosols, J. Geophys. Res., 103, 6043- 6054, 1998.

[9] Hegde P., et al., South Asian dust episode in June 2006: Aerosol observations in the central Himalayas, Geophys. Res. Lett., 34, L23802, doi:10.1029/2007GL030692, 2007.

[10] IPCC- 2007, Report of the IPCC, Cambridge Univ. Press, New York.

[11] Jacobson M. Z., Strong radiative heating due to mixing state of black carbon on atmospheric aerosols, Nature, 409, 695- 697, 2001.

[12] Jayaraman A., Aerosol radiation cloud interactions over the tropical Indian Ocean prior to the onset of the summer monsoon, Current Sci. 81, 11, 1437-1445, 2001.

[13] Kaufman Y. J., Tanre D. and Boucher O., A satellite view of aerosols in the climate system, Nature, 419, 215-223, 2002.

[14] Moorthy K. K., et al., Aerosol climatology over India, ISRO-GBP MWR network and database, Sci. Rep. SR-03- 99, Ind. Space Res. Organ., Bangalore, India 1999.

[15] Pandithurai G. et al., Aerosol radiative forcing over a tropical urban site in India, Geophys. Res. Lett. 31, doi:10.1029/2004GL019702, 2004.

[16] Pant P. et al., Aerosol characteristics at a high-altitude location in centralHimalayas: Optical properties and radiative forcing, J. Geophys. Res., 111, D17206, doi:10.1029/2005JD006768, 2006a.

[17] Pant P., et al., Aerosol characteristics at a high-altitude location during ISRO-GBP Land Campaign-II, Current Sci., 91, 8, 2006b.

[18] Ramanathan V., et al., Indian Ocean experiment: An integrated analysis of the climate forcing and effects of the great Indo-Asian haze, J. Geophys. Res., 106(D22), 28,37128,398, 2001.

[19] Rosefield D., Suppression of rain and snow by urban and industrial air pollution, Science, 287, 1793-1796, 2000.

[20] Sagar et al., Characteristics of aerosol spectral optical depths over Manora Peak: A high - altitude station in the central Himalayas, J. Geophys. Res., 109, D06207, 2004.

[21] Satheesh S. K. and Ramanathan V., Large differences in tropical aerosol forcing at the top of the atmosphere and Earth's surface, Nature, 405, 60 - 63, 2000.

[22] Satheesh S. K., et al., Chemical microphysical and radiatve effects of Indian Ocean aerosols, J. Geophys. Res., 107(D23), 4725, doi:10.1029/2002JD002463, 2002. 
[23] Seinfeld J. H., et al., Regional climate and atmospheric chemical effects of Asian dust and pollution, Bull. Amer. Meteorol. Soc., pp 367-380, 2004.

[24] Stull R. B., An introduction to boundary layer meteorology, Kluwer Academic Publishers, P.O Box 17, 3300, AA Dordrecht, The Netherland, 1999.

[25] Tripathi S. N., et al., Aerosol black carbon radiative forcing at an industrial city in northern India, Geophys. Res. Lett., 32, L08802, doi:10.1029/2005GL02251, 2005.

[26] Twomey S. A., The influence of pollution on the shortwave albedo of clouds, J. Atmos.Sci. 34, 1149-1152, 1977.

[27] Vladimir A. K. and Eichinger W. E., Elastic Lidar: Theory, Practice and Analysis Methods, ISBN 0-471-20171-5, John Wiley \& Sons, Inc. p1, 2004. 